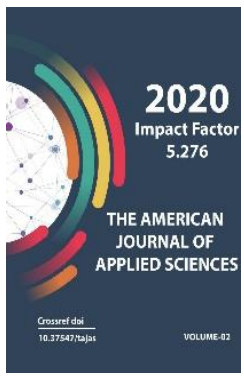

\title{
Research Of Training Loads On The Simulator "Concept -2" In The Preparation Of Youth In Academic Rowing
}

\author{
Zikirillo Nasrullaevich Azimov \\ Uzbek State University Of Physical Culture And Sports, Uzbekistan
}

Copyright: Original content from this work may be used under the terms of the creative commons attributes 4.0 licence.

\section{ABSTRACT}

The article studies the features of the research of training loads on the simulator "concept -2" in the preparation of youthin academic rowing. Academic rowing refers to cyclical sports, which are characterized by a significant display of endurance and speed-power abilities. The complex development of these abilities requires the use of a wide range of training tools and methods.

\section{KEYWORDS}

Physical, Concept -2, Sigma Sport, rowing, Microcycles, training, competitions,distance, Analysis, youth.

\section{INTRODUCTION}

Academic rowing refers to cyclical sports, which are characterized by a significant display of endurance and speed-power abilities. The complex development of these abilities requires the use of a wide range of training tools and methods. At the same time, most of the questions on the method of developing basic physical abilities in young rowers using a rowing simulator are practically not studied. In

recent years, in the training of academic rowers, including for young athletes, it became necessary to include a special "Concept -2" simulator in training sessions. This need is due to the fact that at the age of 15 years, athletes must meet the control 
standards and compete on rowing machinesErgometers at various distances from 500 to 4000 meters. Since there is currently no data on the use of rowing simulators in the yearround training of young rowers, the purpose of our study was to determine acceptable load volumes in the use of the "Concept -2" simulator in the training of young beginners (12-13 years old) and younger boys (14-15 years old).

\section{ORGANIZATION OF RESEARCH}

The study involved athletes of two groups: the first group-the first year of training, young men12-13 years, the second-young men14-15 years of the second year of training. In the first group, the tasks of our work were:

- To familiarize students with the"Concept 2" simulator in General;

- Learn the basics of rowing techniques on the simulator;

- Prepare students for control tests at a distance 500 meters. The second group solved the following tasks:

- Development of speed and power abilities;

- Development of special endurance;

- Working out the pace of rowing and stroke power;

- Preparing students for competitions on rowing simulators at a distance of 1000 meters.

The research was conducted in the period from September 1, 2005 to December 30, 2005. Composition of the first group: number8 people, average age

-13 years, average height- $173 \mathrm{~cm}$, average weight55, $7 \mathrm{~kg}$. Composition of the second group: number-6 people, average age-15 years, average height-182 cm, average weight-
$68 \mathrm{~kg}$. In the first group of subjects, the average heart rate was 80

beats per minute at rest, and in the second62-70 beats per minute at rest, which generally corresponds to the data of physiologists (A. S. Solodkov, E. B. Sologub, 2004). Before the start of classes, all athletes underwent medical examinations. During the training sessions, the heart rate was monitored during work and recovery. During the study period, functional tests were performed with all participants in dynamics: heart rate at rest, blood pressure at rest, 20 squats were performed, and heart rate and blood pressure were measured immediately after exercise, on the second and third minutes of recovery. In the group of first-year beginners, during the first four microcycles, students got acquainted with the rowing simulator and learned the basics of rowing techniques on it. In the next two microcycles, the simulator for these participants was used in complex training sessions, which included stretching exercises and various exercises with their own weight, and therefore rowing on the"Concept -2" was not a tedious load. In subsequent microcycles, young men overcame the segments from 150 to 250 meters, which took time to pass them from 30-35 seconds. at a distance of 150 meters and up to 60 seconds. at a distance of 250 meters, which corresponds to the recommendations of V. G. Nikitushkin and I. S. Epishchev (2004). As training progressed, the athletes of the first group completed four to five repetitions of 150 meters with a rest interval of 5 to 7 minutes or 3 to 4 repetitions of 250 meters with a rest interval of 7 to 10 minutes. At the same time, after a passive rest during 3-4 minutes in the rest of the time, the students performed exercises for relaxation and stretching. 
IN ROWING

\section{Changing the speed of rowing on short sections of group 1}

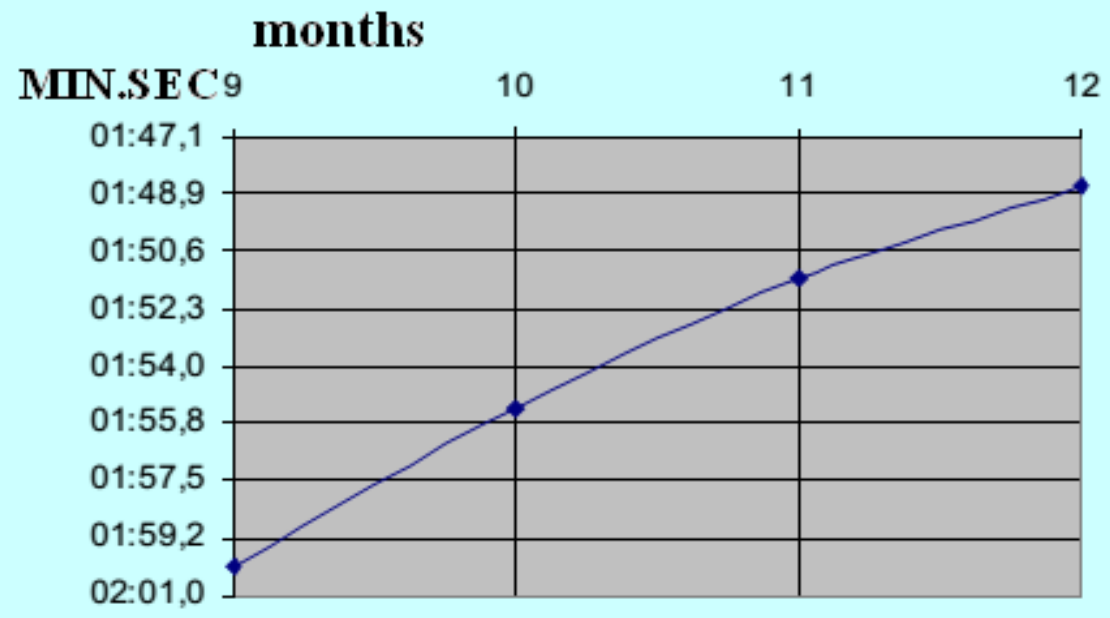

Analysis of the data obtained showed that the majority of young men demonstrate stable speed in short segments, and the average speed is constantly increasing. After the load, the heart rate averaged 174 beats per minute, and during the recovery period- after 2-3 minutes-it decreased to $126-132$ beats per minute, which indicates that this load is tolerable. However, given the significant impact of such loads on the body of young people-Scientific and theoretical journal "Scientific notes", Issue \#19-200624 shifts, they were used infrequently, after two microcycles. Based on pedagogical observations, analysis of diaries and training plans, it was found that in total for the period from the beginning of September to the end of December, novice boys rowing on segments of different lengths on arowing simulator, passed a total of $3.5 \mathrm{~km}$ to $5 \mathrm{~km}$. The results of control tests-rowing at a distance of 500 meters on the rowing simulator "Concept -2" showed an increase in the readiness of students, which gives reason to believe that such loads are acceptable for novice young men. The average speed at a distance of 500 meters increased from 2.01.0 min to1.48.9 min. The data obtained is shown in graph 1 . In the group of the second year of training, starting from the first training microcycle, all the tasks set at this stage of training were consistently solved. Microcycles $\mathrm{C}_{1}$ to 4 numbers were aimed at developing General and special endurance through rowing on a rowing coach- 
re. For this purpose, a distance of 3-4 $\mathrm{km}$ with a heart rate of up to 160 beats per minute was used. The passage began with a single segment, then, as the athletes ' fitness increased, the number of segments increased to 2-3 passes with an interval of active rest of 15-20 minutes, which was filled with calm rowing in the pool or performing exercises for the abdominal muscles, relaxation and stretching exercises. The heart rate during operation and recovery was recorded using a heart rate monitor "Sigma Sport". The pulse was restored at 3-5 minutes after the segment was completed. With such training, the pace was worked out in parallel with the development of endurance rowing, which corresponded to the racing pace of rowing in the main boat for along distance.

\section{Changing the speed of rowing on short sections of group 2}

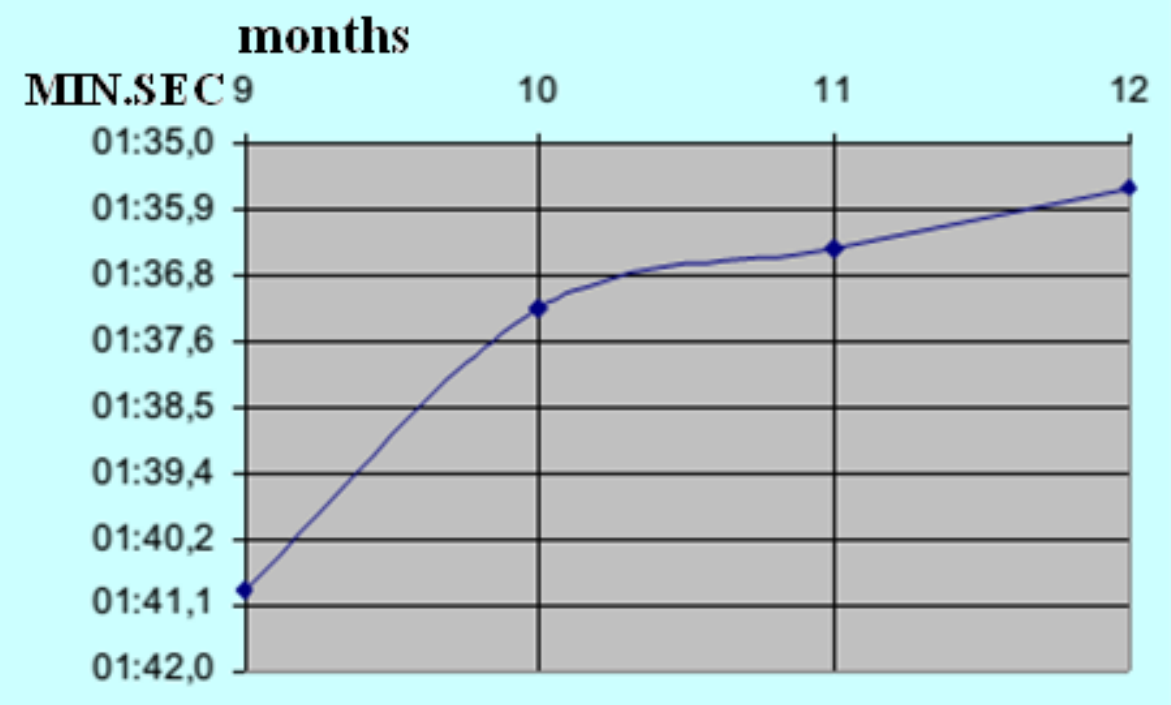

Analysis of the data obtained showed that the majority of young men demonstrate stable speed in short segments, and the average speed is constantly increasing. After the load, the heart rate averaged 174 beats per minute, and during the recovery period- after 2-3 minutes-it decreased to 126-132 beats per minute, which indicates that this load is tolerable. However, given the significant impact of such loads on the body of young people- Scientific and theoretical journal "Scientific notes", Issue 19-2006 24 shifts, they were used infrequently, after two microcycles. Based on pedagogical observations, analysis of diaries and training plans, it was found that in total for the period from the beginning of September to the end of December, novice boys rowing on segments of different lengths on a rowing simulator, passed a total of $3.5 \mathrm{~km}$ to $5 \mathrm{~km}$. The results of control tests-rowing at a distance of 500 meters on the rowing simulator "Concept -2" showed an increase in the readiness of students, which gives reason to believe that such loads are acceptable for novice young men. The average speed at a distance of 500 meters increased from 2.01.0 min to1.48.9 min. The data obtained is shown 
in graph \# 1.In the group of the second year of training, starting from the first training

Microcycle, all the tasks set at this stage of training were consistently solved. Microcycles $C_{1}$ to 4 numbers were aimed at developing General and special endurance through rowing on a rowing coach-re. For this purpose, a distance of 3-4 $\mathrm{km}$ with a heart rate of up to 160 beats per minute was used. The passage began with a single segment, then, as the athletes ' fitness increased, the number of segments increased to 2-3 passes with an interval of active rest of 15-20 minutes, which was filled with calm rowing in the pool or performing exercises for the abdominal muscles, relaxation and stretching exercises. The heart rate during operation and recovery wasrecorded using a heart rate monitor "Sigma Sport". The pulse was restored at 3-5 minutes after the segment was completed. With such training, the pace was worked out in parallel with the development of endurance rowing, which corresponded to the racing pace of rowing in the main boat for a long distance. To test the wiring power and develop speed-power capabilities, we used segments from 250 meters to 750 meters, after which the heart rate reached up to 172186 beats per minute, but after 2-3 minutes of rest it decreased to $114-120$ beats per minute. During the training period from September to the end of December, the boys of the second group completed a total of rowing on short stretches from 10 to $12 \mathrm{~km}$. The analysis of the obtained data showed that in repeated training sessions, the stable speed on short sections when rowing on the"Concept -2" was preserved with a total of 1500-2000 meters. The athletes ' state of health at the end of classes was satisfactory. This is evidenced by the achieved full recovery of working capacity and functional state in a day. It seems to us that rowers 14-15 years old successfully cope with such loads when rowing on a rowing simulator. Indicators of changes in the average speed at a distance of 500 meters in the group of the second year of training increased from 1. $41.1 \mathrm{~min}$. to $1.35 .9 \mathrm{~min}$. The data is shown in graph 2. After a high-speed and power load, the young men performed aerobic work of a restorative nature at the next training session (running, rowing, skiing). Rowing on the sections was conducted once in a weekly microcycle.

Pedagogical observations have shown that when repeated passage between 250 and 500 meters, the stability of the results is maintained when young men pass the total volume of 1500-2000 meters. The adequacy of such a load, the readiness of the body of the student is confirmed by the nature of changes and the duration of functional shifts. When walking the total volume of more than 2000 meters with maximum intensity, young men show results with a tendency to reduce the speed of rowing and the power of rowing, they have impaired coordination of movements in the rowing technique. At the same time, with a drop in the speed of rowing, young men show signs of severe fatigue: blood pressure rises to significant levels, there is a feeling of nausea, dizziness. All this testifies to the lack of preparation of young men14-15 years old for such a load. The nature of changes and duration of functional shifts also indicate that training loads are inadequate for large volumes of speed and strength work of maximum intensity.

\section{CONCLUSION}

Therefore, the permissible volume of speed and power work on the rowing simulator "Concept -2" for the specified age should be considered the order of 2000 meters in total. A positive aspect of using rowing simulators in the training of young men is the "dynamic correspondence", which includes the main principles: the amplitude and direction of movement, the amount of dynamic effort, the speed of maximum effort, the mode of muscle operation correspond to the main motor action. 
A positive aspect of using rowing simulators in the training of young men is the "dynamic correspondence", which includes the main principles: the amplitude and direction of movement, the amount of dynamic effort, the speed of maximum effort, the mode of muscle operation correspond to the main motor action.

\section{REFERENCES}

1. Alekseenko, E.M. Strength, technique, speed / E.M. Alekseenko // Rowing in Russia Moscow: 1998.- N 1.- p. 22-23.

2. Belenkov, A.G. Endurance / A.G. Belenkov // Rowing in Russia. Moscow: 1998. - N 1. p. 18-20.

3. H.L.Fourie, I.W.Fourie An Introduction to Rowing UK, 2013

4. John Chase Power to the Raddle: Exercises to Improve your Canoe and Kayak Paddling USA, 2014

5. M.I.Folgar, F.A.Carceles, J.R.Mangas Training sprint canoeing 2015. 